\title{
FERNANDO DEL PASO Y EL ARTE DE LA RENOVACION
}

\author{
POR \\ ROBIN WILLIAM FIDDIAN \\ University of Newcastle upon Tyne, England"
}

En 1917, en un artículo que llevaba el título "México: una literatura en movimiento", Nelson Marra celebró la aparición de una novela, José Trigo de Fernando del Paso, que, junto con la compilación Poesía en movimiento de Octavio Paz y Zona sagrada, de Carlos Fuentes, daba una señal inequívoca de una nueva vitalidad en las letras mexicanas contemporáneas. Aventurando la atrevida opinión: "Esta novela es para el pueblo mexicano lo que la Biblia representó para el pueblo hebreo", Marra calificó a José Trigo de "novela de vanguardia" y vaticinó que sería "profundamente admirada y entendida [...] dentro de muchos años"1. Las declaraciones de Nelson Marra son dignas de ser recordadas aquí, en parte por su pintoresca hipérbole $\mathrm{y}$, sobre todo, por lo acertado de su profecía referente a las fortunas críticas de la novela de Fernando del Paso. Porque, si Jose Trigo tuvo cierto impacto en los círculos de la crítica nacional cuando se publicó en 1966, las opiniones de que fue objeto en ese momento ni tuvieron una amplia difusión ni fueron unánimemente favorables al nuevo autor ${ }^{2}$. Y así en los años siguientes, aun cuando comentaristas como Luis Leal y Donald Shaw vendrían a conceder un puesto destacado a José Trigo en la evolución de la novela mexicana contemporánea ${ }^{3}$, otros como Jorge Ruffinelli, seguirian reacios a incluir el nombre de del Paso instintivamente en la lista de cabezas de serie de la narrativa del país4

\footnotetext{
${ }^{1}$ Nelson Marra, "México, una literatura en movimiento", Temas, 14, Montevideo, octubrediciembre 19677), 28-32.

${ }^{2}$ Una reacción hostil fue la de Emir Rodríguez Monegal, en El boom de la novela latinoamericana. (Caracas: Editorial Tiempo Nuevo 1972), p. 104. En México, más equilibrada fue la postura de Ramon Xirau, en "José Agustín, Navarrete, Del Paso", Diálogos, III, 2 (marzo-abril 1967), 24-26.

${ }^{3}$ Luis Leal, "La nueva narrativa mexicana", Nueva narrativa hispanoamericana, II, 1 (enero 1972), 89-97. Donald L. Shaw, Nueva narrativa hispanoamericana (Madrid: Cátedra, 1981), pp. 162-166.

${ }^{4}$ Jorge Ruffinelli, "Notas sobre la novela en México (1975-1980)", Cuadernos de Marcha, 14 (julio-agosto 1981), 47-59.
} 
Es sobre todo a partir de la publicación de su segunda novela, Palinuro de México (1977) cuando la opinión crítica empicza a cristalizar en torno a Fernando del Paso, reconociendo su importancia no solamente en un contexto nacional, sino también a escala continental. Galardonada con el Premio de Novela México de 1975 y el Premio Rómulo Gallegos de 1982, Palinuro sitúa a del Paso en la primera fila de los narradores americanos, y estimula una aproximación a los fundamentos de su obra. Una nueva edición de Jose Trigo (México 1883) significa la recuperación de ese texto, coincidiendo con una revisión general de los supuestos lcóricos y los logros prácticos de la narrativa hispanoamericana de los años del booms.

Cuando se publica Noticias del Imperio, en noviembre de 1987, del Paso queda consagrado como uno de los maestros de la narrativa mexicana contemporánea. En los términos de una comparación propuesta originalmente por Nelson Marra, ahora del Paso no sólo comparte la aclamación crílica con Carlos Fuentes, sino que convence a más de un comentarista de que "cl mejor narrador que tiene hoy cn día México" es él, y no cl autor de Terra nostra y Cristóbal Nonato ${ }^{6}$. Para la mayoría de nosotros, tal juicio de valor cstá de más en un plantcamiento scrio de la obra de uno y otro autor. Pero, una comparación de Fernando del Paso con Carlos Fuentes puede ser reveladora a la hora de intentar definir el lugar ocupado por el primero de estos escritores dentro del panorama de las letras mexicanas.

Anclado en el mismo contexto político-cultural que Fuentes, del Paso se interesa como ćl por indagar en el destino del hombre mexicano visto como ser en la historia y por explorar las raíces profundas y enmarañadas de su identidad cultural. Para cumplir con estos objetivos, ccha mano de un variado repertorio de procedimicntos tćcnicos, y demuestra una rara habilidad para construir vastas estructuras novelísticas que se asemejan a monumentos barrocos o frisos de complicado relieve? ${ }^{7}$ Entonces, junto con Fuentes, se perfila como el agente más significativo de la tecnificación narrativa en México en los años 60 y 70. Pero no hay que olvidar que tiene sicte años menos que Fuentes, y que publica su primera novela cuando a éste se le reconoce ya como un importante promotor y protagonista del creciente fenómeno literario-comercial de la nueva narrativa hispanoamericana.

${ }^{5}$ Véase como ejemplo el importante estudio de Gerald Martin, "Boom, Yes, 'New Novel', No; Further reflections on the Optical Illusions of the 1960s in Latin America".

${ }^{6}$ La opinión es de Alberto Arankowsky, en una reseña de Noticias publicada en Excelsior, 29 de enero de 1988 . Hay una copia de la reseña, sin referencia al número de la página, en el archivo de la Dirección de Literatura del Instituto Nacional de Bellas Artes situada en la Torre Latinoamericana, en México, D. F.

${ }^{7}$ Dice del Paso, "El interés por la historia que tenemos Carlos Fuentes y yo se asemeja mucho. Tendemos a la epopeya, al gran fresco, al mural" Véase la entrevista con Gerardo Ochoa Sandy en Sábado, suplemento de Unomásuno, 23 de julio de 1988, p. 2. 
Desde una perspectiva generacional, del Paso es coetánco de Gustavo Sáinz, José Emilio Pacheco, Salvador Elizondo y José Agustín. Sin cmbargo, no es fácil cncasillarlo en ninguna de las categorías de la novelística mexicana de la ćpoca: no le van ni la etiqueta ni los postulados de la "Onda", tampoco los de la llamada escuela de la "Escritura". Para ser más precisos, podríamos clasificarlo como correligionario de Fucntes, heredero de Revueltas y discípulo de Arreola y Rulfo Pcro Fernando del Paso se mueve por sus caminos propios. Con Marco Antonio Montes de Oca es el único escritor mexicano de su generación que asiste al Segundo Congreso Latinoamericano de Escrilores, celebrado en México en 1967. Cuatro años más tarde se marcha a vivir al extranjero, donde consigue hacerse económicamente independiente, si bien aumenta sus ingresos con el dinero que le dan por trabajos periodísticos encargados por los medios de comunicación de su país. Y defiende un credo poético personal que le distingue de los compañeros de su generación.

La experiencia del exilio voluntario tiene un valor positivo en la vida de Fernando del Paso. Entra cn contacto con escritores latinoamericanos tan dispares como Mario Benedeut, Gabriel García Márquez y Guillermo Cabrera lnfante, y estrecha sus vínculos con la tradición literaria continental. Reconoce una deuda con Asturias, Borges, Marechal, Guimaraes Rosa y Carpenticr; descubre una afinidad con Cortázar y Cabrera Infante, cuyo asalto a los valores de la cultura judeo-cristiana y afán de renovación lingüística reflejan su propia postura filosófica y artística, y se siente identificado con aquellos escritores como García Márquez y Roa Bastos, que se proponen cxaminar las condiciones de colonización y marginalidad en que viven millones de seres humanos en los paises de Latinoamérica. "Soy definitivamente mexicano y latinoamericano y con mente de país colonizado", afirma en una entrevista con Maruja Echegoyen". Y, en c1 discurso pronunciado al recibir el IV Premio Internacional de Novela "Rómulo Gallegos" cn Caracas, el 3 de agosto de 1982, vuelve a insistir, "Mas allá de mi patria chica, mas acá de la ciudadanía del mundo, soy, scré sicmpre un latinoamericano"10.

La relación de Fernando del Paso con las corrientes literarias del continente americano es un tema que no puede menos de hacerse notar aqui. Pero, para los propósitos de nuestro trabajo, pasarả a ocupar un segundo plano, dando paso a una

\footnotetext{
${ }^{8}$ Rulfo reconocía que Fernando del Paso podía ser discípulo suyo, en conversación con Emesto González Bermejo, "Juan Rulfo: "La literatura es una mentira que dice la verdad", Revista de la Universidad de México XXXIV, 1 (sctiembre 1979), 8

"Maruja Echegoyen, "Nuevas conversaciones con Fernando del Paso", Cuadernos de marcha, 17-18 (sctiembre 1983), 32.

${ }^{10}$ El texto del discurso, titulado "Mi patria chica, mi patria grande", está reproducido en Casa de las Américas, 136 (enero-febrero 1983), 154-160 (160)
} 
consideración de las claves de su producción novelística. En las páginas que siguen se pasará revista a tres aspectos de la obra delpasiana, a saber: la relación que tiene con el mundo de la historia; sus pretensiones y mecanismos totalizadores y la poética, o teoría del fenómeno estético, que sustenta a sus novelas. Este esquema no pretende ser exhaustivo, pero sí dar cuenta de aquellos aspectos que considero fundamentales en las tres novelas de nuestro autor.

\section{HISTORIA Y NOVELA: PRE-TEXTOS, TEXTOS Y CONTEXTOS}

Una constante de las novelas de Fernando del Paso es su inspiración en la realidad histórica nacional que hace un papel variable de contexto o pre-texto del quehacer literario. Así, José Trigo tiene su punto de partida en la huelga de los ferrocarrileros mexicanos de 1958-59, encabezada por dirigentes sindicales entre los que se destacó Demetrio Vallejo, que fue sojuzgada por fuerzas militares y policiales cumpliendo con las órdenes del Presidente Adolfo López Maleos. Palinuro de México está inspirado, en parte, por los acontecimientos políticos de 1968, cuando el presidente de México, Gustavo Díaz Ordaz autorizó la represión masiya y sangrienta de cientos de estudiantes en la plaza capitalina de Tlatelolco. Y Noticias del Imperio se basa en la intervención francesa que intentó implantar la monarquía Habsburgo de Maximiliano y Carlota en México, y que culminó con la ejecución de Maximiliano en el Cerro de las Campanas en Querétaro, el 19 de junio de 1867.

Enfocando los tres textos en su conjunto, cabe observar que sólo el tercero se aproxima al género de la novela histórica, aunque esta designación es rechazada por el autor ${ }^{11}$. Noticias novela unos hechos de la historia mexicana del siglo diecinueve y además indaga consciente y profusamente en la naturaleza y convenciones del género histórico. José Trigo y Palinuro reflejan unos hechos de la realidad contemporánea, proyectándolos contra un trasfondo temporal que abarca casi cinco siglos de vida nacional en el caso del primer texto, y las casi siete décadas del siglo veinte - con referentes como la Revolución Mexicana y la Primera Guerra Mundial — en el segundo. Para apreciar el variado tratamiento de los temas históricos en las tres novelas, conviene someterlas a un análisis detenido ${ }^{12}$.

"Véase Fernando García Ramírez, "Noticias de un loco amor", en el Semanario Cultural de Novedades, núm. 303 (7 de febrero de 1988), 7.

${ }^{12}$ Manejo las siguientes ediciones de las novelas de Fernando del Paso: José Trigo, 2da edición (México: Siglo XXI, 1969); Palinuro de México (México: Joaquín Mortiz, 1980), Palinuro en adelante; Noticias del Imperio: Editorial Diana, 1987) Noticias en adelante. Mi interés en la obra de Fernando del Paso remonta a 1977 cuando se publicó la primera edición de Palinuro en Madrid y ha cristalizado en los siguientes estudios: "Palinuro de méxico: A World of Words", BHS, LVIII (1981), 121-133; "Beyond the Unquiet Grave and the 
En José Trigo, la realidad histórica sirve mayormente de pretexto para un cuidadoso proceso de elaboración artística. La estructura narrativa de la obra se basa en acontecimientos, personajes y fechas que pertenecen al mundo real, pero estos datos son transformados y supeditados a un diseño que sustrae los eventos de su contexto concreto para fecharlos en 1960, mezclándolos confusamente con acontecimientos de la década de los cuarenta cuando nació el charrismo sindical. En dos capítulos que tratan de la Guerra de los Cristeros de 1926-1927, el autor compagina un presunto material histórico con otro geográfico que es a todas luces ficticio. Al nivel formal, la novela asimila una historia fragmentada y rudimentaria a un discurso que, en vez de seguir una narración lineal, se afana por construir una estructura piramidal de analogías, inversiones y simetrías. Y el material histórico es aprovechado en gran medida para fines lingüisticos y textuales: el autor parodia el discurso solemne y piadoso de un "vanílocuo" cura cristero, y se vale de la historia de Nonoalco-Tlatelolco "donde se perdió la gran batalla de Tenochtitlán [...] donde se levantó el primer colegio de América [...], donde existió el tianguis más grande de América", para re-escribir las suntuosas Crónicas de la vida y las costumbres del Tenochtitlán colonial ${ }^{13}$.

Sobre todo, asistimos en José Trigo a la contaminación de un posible discurso histórico por otro mítico, constituido por elementos arquetípicos que del Paso no vacila en calificar de "eviternos". El personaje histórico de Demetrio Vallejo se transforma, conforme con este proceso, en un ente de ficción llamado Luciano quien reviste características claramente paradigmáticas, aunque no exentas de ambigüedad. Vemos a Luciano en una serie de situaciones entre heroicas y vulgares donde su conducta recuerda la del dios azteca Quetzacóatl, y, en un marco de referencia cristiano, la de Jesucristo. Los demás personajes también se ajustan a moldes arquetípicos. Manuel Angel, el antagonista de Luciano, está hecho en las imágenes de Tezcatlipoca y el angel caído, Lucifer: la madrecita Buenaventura corresponde a Tlazolteotl, la madre de los dioses en la antigua religión de los aztecas.

Para la crítica argentina Nora Dottori, el diseño mítico de José Trigo supone una mixtificación de la realidad por parte de Fernando del Paso, quien abdica de su responsabilidad con el proletariado mexicano y traiciona los preceptos del cambio y el progreso históricos ${ }^{14}$. La acusación es seria, pero equivocada con

Cemetery of Words: Myth and Archetype in Palinuro de México", Ibero-Amerikanisches Archiv, VIII (1982), 243-255; y "A Case of Literary Infection: Palinuro de México and Ulysses" Comparative Literature Studies, XIX (1982),220-235.

${ }^{13}$ Véanse "Revelaciones y anticipaciones de Fernando del Paso y Miguel Angel Asturias", reproducidas por Juan Carvajal en La Cultura en México, 225 (8 de junio de 1966), 3.

${ }^{14}$ Nora Dottori, "José Trigo: el terror a la historia", en Nueva novela latinoamericana, ed. J. Lafforgue, II vols., I (Buenos Aires: Paidós, 1969), 262-299. 
respecto a los planteamientos políticos y estéticos del libro. En principio, José Trigo carccía de intencionalidad política: "Mi intención no fuc que tuvicra un contenido social determinado o predeterminado", ha dicho del Paso"; tampoco pretendía que fuera un texto mimético, sino que optaba por traducir cl conflicto entre el sindicato de Demetrio Vallejo y el Estado en términos sicoanalíticos que giran alrededor de los temas de la legitimidad, la autoridad y la familia. La expresión de estos conceptos por medio de símbolos y leyendas derivados de las mitologías aztecas y cristianas es una consecuencia lógica de la influcneia de estos dos sistemas culturales en la configuración de la cosmovisión mexicana moderna.

Puestos a rastrear una concepción de la historia en Jose Trigo, hay que admitir que ésta sería pesimista y derrotista. Pero existen otros elementos de contenido ideológico en el libro que entran dircctamente en conflicto con una visión negativa del destino humano, como son la promesa de la regeneración en el orden natural y la confianza en una resurrección simbólica de la figura del héroc. Estos clementos son una parte esencial de la cosmovisión del autor, que se incorpora al discño mítico que engloba el material narrativo de José Trigo.

La relación del texto literario con el mundo de la historia es más directa en Palinuro, que recoge la reacción de protesta y horror de gran parte de la población mexicana ante la violenta represión gubernamental de los cstudiantes de su país en octubre de 1968. Sin lugar a dudas, Palinuro demuestra el compromiso de su autor con una realidad política "que nos persigue todos los días, en la calle, en la televisión, en la prensa", y traduce su rechazo de las dictaduras, de las empresas multinacionales, de los asesinos del Che Guevara, de los que arrojaron la bomba a Hiroshima y el napalm en Victnam. De los que hiricron de muerte a un cstudiante en la Plaza Mayor de México ${ }^{16}$.

En su recreación de los acontecimientos de Tlatelolco, del Paso culpa de la tragedia al Presidente y su gobierno, al Partido Revolucionario Institucional, al Ejército y la Policía, y a una burguesía acomodaticia. Usa la sátira para denunciar la corrupción y la injusticia que rcinan en México, y deficnde el movimicnto estudiantil cuyas reivindicaciones políticas vincula con las de Che Guevara y los estudiantes franceses de mayo 1968.

Al mismo tiempo que cumplía con esta obligación ética, del Paso seguía fiel a los criterios estéticos y a la cosmovisión que inspiraron su primera novela. Palinuro ostenta un ambicioso grado de claboración artística que se manifiesta en la complejidad de sus atributos genćricos y la configuración de la estructura narrativa de acuerdo con un patrón arquetípico. La historia de $P$ alinuro cstábasada

\footnotetext{
15 "Revelaciones y anticipaciones de Fernando del Paso y Miguel Angel Asturias", 3.

${ }^{16}$ Fernando del Paso, "La imaginación al poder. El intelectual y sus medios" Revista de la .Universidad de México, XXXIV, 2 (octubre 1979), 15.
} 
cn la del desafortunado personaje virgiliano, Palinurus, cuya muerte y agonía se narran en los libros V y VI de la Eneida. Por medio de esta analogía y otras referencias mitológicas, Palinuro se convierte en un personaje arquetípico. "mitad humano y mitad escultura, mitad desconocido y mitad héroe" (p.97), y sus experiencias se ajustan a un patrón universal y atemporal, de iniciación y pérdida de la inocencia, degradación y aislamiento, y muerte y resurrección.

De entrada, llama la atención el gran parecido que existe entre este esquema y la historia de Luciano en José Trigo. Pero más importante todavía es cl cambio de énfasis en la disposición del contenido ideológico de las dos obras: si JoséTrigo dejaba sin resolver la tensión entre una visión negativa de la historia y un mensaje de regeneración, Palinuro consiguc dar expresión cabal a la cosmovisión del autor quien, al mismo ticmpo que lamenta la muerte de un estudiante sacrificado en aras de la historia, confía en el resurgimiento del heroísmo y afirma los valores espirituales de la vida. Así, Palinuro prolonga una digna tradición literaria, cjemplificada en cl Ulises de Joyce, Adan Buenosayres de Marechal, y Rayuela de Cortázar, que encarna los más generosos ideales humanistas de la civilización occidental.

La última novela de Fernando del Paso se distingue de las anteriores por la amplitud de su contenido histórico y por los términos en que el autor plantea su doble responsabilidad de novelista c historiador. Noticias del Imperio sintetiza una cnorme cantidad de información sobre la intervención francesa y el cfímero imperio de Maximiliano en México, situando estos acontecimientos en un doble contexto: uno, continental, que abarca la expansión del poderío yanqui en el continente americano, la abolición de la esclavitud en el Brasil, y los intentos de crear una alianza entre las repúblicas independientes de Hispanoamérica; el otro, intercontinental, que abarca la historia de la dinastía Habsburgo y las actividades de sus distintas ramas, tanto dentro como fucra de Europa. En base a los esfuerzos prodigiosos de investigación y contextualización de que da testimonio Noticias, no cabe duda de que el autor se encuentra en su derecho de hablar de ciertas aportaciones que él ha hecho a la historiografía ${ }^{17}$. Pero, hay que insistir en un hecho clemental: del Paso, en primer término no es historiador, y si ha querido hacer historia en Noticias es con arreglo a un criterio y un método que son muy particulares.

Una explicación del planteamiento del libro se encuentra en cl penúltimo capítulo, donde del Paso dicla su opinión sobre el ineludible compromiso de artistas $\mathrm{c}$ intelectuales con $\mathrm{el} \mathrm{mundo} \mathrm{histórico} \mathrm{en} \mathrm{que} \mathrm{viven.} \mathrm{Considerando} \mathrm{las}$

\footnotetext{
${ }^{17}$ Véase la cntrevista realizada por Enriqueta Cabrera y publicada en tres partes en El Día, 23, 24 y 25 de marzo de 1988. El comentario del Sr. del Paso referente a la historiografía aparece en el número del 25 de marzo, sin página.
} 
posibles estrategias que un escritor puede adoptar ante el reto de la historia, opta por un método de trabajo que consiste en conciliar todo lo verdadero que pueda tener la historia con lo exacto que puede tener la invención. En otras palabras, en vez de hacer a un lado la historia, colocarla al lado de la invención, de la alegoría, e incluso al lado de la fantasía desbocada (p.641).

Noticias pone esta propuesta en práctica entrelazando capítulos en los que prevalece un discurso histórico, más o menos puro, con otros que contienen el contradictorio monólogo de Carlota, que muere enloquecida en el Castillo de Bouchout en 1927. En el orden de los conceptos, del Paso insiste en borrar las distinciones que convencionalmente existen entre la realidad y la ficción, llegando a recalcar los elementos fantásticos, "casi irreales", que componen la historia concebida como una "fiesta delirante" (p.115). Lo que en un principio le atrajo al tema de Maximiliano y Carlota, dice, "fueron los detalles surrealistas, casi irreales, de [su] historia, como es la situación de un emperador rubio, de ojos azules y un metro ochenta en un estado como México"18. En tales circunstancias la realidad se confunde con la literatura, adquiriendo visos de una novela de aventuras 0 , como observa el autor, de un melodrama (pp. 636 y 638).

A esta concepción heterodoxa de la historia se añade la conciencia que tiene del Paso de los defectos y limitaciones de la historiografía que, como empresa intelectual, está contaminada en sus orígenes por impurezas ideológicas y psicológicas ("Existen muchas historias no sólo particulares sino cambiantes, según las perspectivas de tiempo y espacio desde las que son 'escritas"' [p. 638]), y sujeta a determinantes lingüísticos y textuales que son decisivos en su elaboración. Del Paso reconoce que el lenguaje que usan los historiadores es todo menos inocente; también, que la historia tiene un fuerte componente textual en cuanto se escribe en textos que derivan de otros textos que constituyen las distintas capas, por así decirlo, de un palimpsesto. Todo lo cual redunda en prejuicio de1 valor didáctico de la historia - escrita u oral-que, si bien puede servir para ampliar y "corregir"'interpretaciones existentes. nunca podrá trascender sus limitaciones metodológicas.

Dados estos reparos, no sorprende que los objetivos fundamentales del autor en Noticias sean otros que los puramente historiográficos. En el fondo, a lo que aspira es a conseguir una recreación poética de las experiencias de Maximiliano y Carlota, que diera cabida a la invención y la ịmaginacion, admitiendo no sólo lo que fue sino también lo que pudo haber sido. Y, en un planteamiento que parece ser intencionado, aspira a aliviar la conciencia nacional de un complejo de culpabilidad ("angustia", "mala conciencia", "remordimientos", "culpa") por el trato indigno y nada compasivo dado a los Emperadores, no tanto durante su estancia en

${ }^{18}$ Véase la entrevista con J. M. Plaza en Diario 16 (Madrid, 26 de octubre de 1987), s.p. 
México como a partir del trágico final de la misma. Citando a Rodolfo Usigli, quien anotaba en el prólogo de Corona de sombra "que sólo México tiene derecho a matar a sus muertos y que sus muertos son siempre mexicanos", el autor implícito de Noticias acepta que:

Así es: el problema no es que en México hayamos matado a Maximiliano, que en México, tal vez, hayamos vuelto loca a Carlota: el problema es que a ninguno de los dos los enterramos en México [...]. Ninguno de los dos, ni él ni ella, quedaron integrados a esta tierra fertilizada al parejo con los restos de todos nuestros héroes $y$ todos nuestros traidores (p. 643).

En la opinión del autor, la recuperación de los Emperadores es una necesidad urgente para el bienestar espiritual del pueblo mexicano, y una tarea que urge a los que hacen y escriben su historia y su literatura. La historiografía poética de Fernando del Paso puede ser un medio privilegiado para alejar los espectros de la historia, dando entierro, por fin, a "las almas de los insepultos [que] reclaman siempre su abandono" (p. 643).

\section{FERNANDO DEL PASO Y EL IMPULSO TOTALIZADOR}

La búsqueda de una síntesis entre los antinomios: historia y poesía, realidad y mito, razón y fantasía, es una constante de las novelas de Fernando del Paso, producto en parte de su adherencia a la cosmovisión surrealista que, en su vertiente bretoniana, abogaba por una resolución de los contrarios. Al mismo tiempo, deriva también de su relación con una tradición europea y americana de la "ficción total" que empieza a formarse en la obra de Joyce, Borges, Asturias y Sábato, y alcanza su más alta expresión en la novela hispanoamericana de los años sesenta, en la obra de escritores como Lezama Lima, Vargas Llosa, Roa Bastos, y Donoso. En la literatura mexicana no cabe duda de que el más célebre protagonista de este fenómeno es Carlos Fuentes. Pero no le va en saga Fernando del Paso, cuya obra completa es un monumento a las posibilidades de la novela total.

El hecho está reconocido por el mejor comentarista sobre el tema, el novelista - también mexicano- Gustavo Sainz, quien ofrece una detallada descripción de lo que llama la "narrativa enciclopédica", tomando ora Terra nostra de Carlos Fuentes, ora Palinuro, de punto de referencia. Según Sáinz, la narrativa enciclopédica es una "categoría literaria" que posee las siguientes características esenciales: I) pone en juego, bajo una perspectiva crítica, la totalidad de conocimientos y creencias que componen una cultura, II) usa elementos épicos en la organización de un material narrativo que desborda los límites convencionales 
de la novela, III) hace una detallada descripción de una tecnología o, cuando menos, una ciencia, y IV) abunda en una variedad de estilos narrativos y procedimientos retóricos. Terra nostra y Palinuro son clásicos del género, juntos con Don Quixote, Moby Dick,Ulises, y Gravity's Rainbow de Thomas Pynchon ${ }^{19}$. Fernando del Paso siente una gran afinidad con esta tradición, como demuestran algunas declaraciones suyas. En una entrevista celebrada en honor del centenario del nacimiento de Jancs Joyce, afirma que :

Ia intención totalizadora de un libro — que para algunos críticos y muchos autores incapaces de llevar a cabo tal empresa parecería ser una especie de sacrilegio"es lo único que puede dar sentido, en nuestra época, a un libro ${ }^{20}$.

En otra ocasión recalca la permeabilidad de la novela a una realidad, cuyos estímulos juzga infinitos, y ofrece una definición de sus propios libros, no como macrocosmos sino como microcosmos:

Nunca he pretendido decirlo todo de todo, sino nada más todo de algo, todo de un microcosmos, de un pequeño mundo que fije sus propias dimensiones y sus reglas de juego ${ }^{21}$.

En José Trigo cl microcosmos indicado tiene sus raíces en la zona capitalina de Nonoalco-Tlatelolco, y comprende su historia, folklore, costumbres sociales, identidad cultural, entorno arqucológico $\mathrm{e}$ industrial, clc. La voluntad enciclopédica del autor se muestra en aquellas secciones de la narración que intentan agotar un campo semántico, como, por cjemplo, la tipología de los comestibles que se habrían encontrado en el gran mercado de América cnumerados cn cl capítulo VIII de la segunda parte de la novcla--y la cxploración cxhaustiva del tema del ferrocarril - la rama tecnológica cuyo análisis no puede faltar, según Säinz, en la narrativa enciclopédica. La presentación de este material narrativo se hace de acuerdo con las normas del géncro total, barajándose los modos dramáticos, ćpicos, históricos, salíricos, mágicos, y líricos en una narración cambiante y polifacética.

Otro aspecto relevante de José Trigo es su condición. de summa de la literatura mexicana. Del Paso se dedica a componer un texto que recoge los más variados

\footnotetext{
${ }^{19}$ Gustavo Sainz, "Carlos Fuentes: A Permanent Bedazzlemenl", trad. Tom J. Lewis, World Literature Today, LVll, 4 (otoño 1983), 568-572.

${ }^{20}$ Este comentario del autor está recogido en mi artículo "James Joyce y Fernando del Paso" Insula, 455 (octubre 1984), 10.

${ }^{21}$ Véanse las declaraciones del Sr. del Paso a Luis Sánchez Bardón y Javier Goñi enTriunfo, 788 (Madrid, 4 de marzo de 1978), 48-49.
} 
géneros y cstilos de una tradición nacional que incluyc la pocsía nahuatl, las Crónicas de la época colonial, la Novela de la Revolución, cl estilo antirretórico de Rulfo, y muchos clementos más. A primera vista, cl proyecto omnivoro del autor parece pecar de caprichoso. Sin embargo, cstá plenamente justificado en cuanto contribuye a la creación de una perspectiva que, en las palabras de Gustavo Sáinz, englobaría "la totalidad de conocimientos y crecncias" que configuran una cultura nacional. Como hemos podido constatar, Jose Trigo mancja un amplio abanico de conocimientos históricos y mitológicos con cl fin de facilitar una comprensión de la cultura mexicana; la incorporación de una dimensión literaria al proyecto complementa las perspectivas del narrador y de la madrecita Buenaventura, y ensancha sensiblemente cl panorama cultural de la novcla.

En Palinuro la conciencia que raya en la omnisciencia está repartida entre el primo Waltcr y cl abuclo Francisco. Wahter, "cl sabclotodo" (p. 268), secaractcriza por su crudición enciclopédica en materias de historia, litcratura, filosofía, música, arte, mitología y, especialmente, cn medicina, una de cuyas ramas - la anatomíaconstituye la ciencia en la cual la novela es abrumadoramente experta. Los conocimicntos del abuelo Francisco son más profanos pero no menos exıcnsos: abarcan los tex tos y autores más célcbres de la literatura mundial, a los que convoca para que asistan al segundo nacimiento de Palinuro en las últimas páginas vertiginosas y triunfales de la novcla. Allí, al citar a personajes tan dispares como Pedro Páramo, Remedios la Bclla, Tom Sawyer, Madame Bovary y cl Hombre sin Cualidades, el abuclo fija las dimensiones del microcosmos de Palinuro, colocando a su nieto en un contexto universal que definc los úllimos contornos del libro.

La ampliación del horizonte cultural en Palinuro es un hecho interesante, explicable en parte en función de la voluntad totalizadora que necesita una temática más extensa que el conjunto de temas tratados en José Trigo. Dueño de un peculiar temperamento artístico, Fernando del Paso ansiaba nuevos espacios en los que desenvolverse; una cultura de trazas universales proporcionaría una matcria prima casi infinita para los proyectos más ambiciosos y audaces, como cl del capítulo final de $P$ alinuro, que promete una relación extravagante de "Todas las rosas, todos los animales, todas las plazas, todos los personajes del mundo". Al mismo ticmpo, la nueva orientación universalista en las novelas de del Paso correspondería a una toma de conciencia por parte del autor de la pluralidad de sus antecedentes culturales. Al marcharse a Londres, en 1971, había sentido la necesidad de "confirmar todo lo que de occidental y curopeo y judeocristiano tenían y tienen mi cultura y mis costumbres, mis tradiciones" ${ }^{22}$. Nada más natural, entonces, que su segunda novela incorporara clementos de la mitología greco-romana, el género épico, la Commedia dell'Arte, cl Ulises de Joyce, y otros logros de la civilización

${ }^{22}$ Fernando del Paso, "Mi patria chica, mi patria grande", 156. 
europea que del Paso, siguiendo a Borges, identifica con un patrimonio universal al que tiene acceso cualquier escritor hispanoamericano.

En Noticias la sintesis de elementos contrarios y complementarios que constituye el tejido de la novela total se da en diversos niveles del texto. Un factor importante en la creación de un microcosmos diversiforme es la combinación de múltiples discursos opuestos (oral/escrito, analfabeto/letrado, histórico/fantástico, etc.). Pero ningún componente desempeña un papél tan crucial como el personaje de Carlota, quien aparece como la portadora ideal de una visión totalizadora de la realidad. Hay que reconocer el tremendo acierto de Fernando del Paso en escoger como sujeto de la ficción un personaje histórico cuyas experiencias vitales son de por sí una especie de metonimia de "toda una época, todo un concepto de la historia y del destino del hombre" (p.630). En un sentido casi literal, Carlota representa al sistema monárquico europeo, tal coma ella indica en una lista incompleta de sus parentescos: "Soy María Carlota, prima de la Reina de lnglaterra [...], hija de Leopoldo Príncipe de Sajonia-Coburgo y Rey de Bélgica [...], sobrina del Príncipe Joinville, y prima del Conde de París". Trasladada a México, su experiencia es igualmente paradigmática, ya que llega a simbolizar el encuentro del Viejo Mundo con el Nuevo. Asume los títulos fantásticos de "Regente de Anáhuac, Reina de Nicaragua, Baronesa del Mato Grosso, Princesa de Chichén Itzá" (p. 13), y se identifica con sus súbditos hasta el grado de sentirse "madre de todos los indios y todos los mestizos, madre de todos los blancos y los cambujos, los negros y los saltapatrases" (p. 644). Entonces encarna una nueva totalidad política y racial.

La locura de Carlota abre otras perspectivas sobre su carácter, que son utilizadas magistralmente por el autor. Del Paso aprovecha su insania, _-"una especie de ciclotimia entendida como psicosis maníaco-depresiva, en la que se alternan la euforia y la melancolía" (p.600)—, para fabricar una conciencia que es una hipérbole absoluta. Carlota en Noticias tiene una capacidad fabulosa para "ver el mundo en una sola gota de agua que contenía todas las aguas del mundo" (p.489); esa facilidad la ayuda a " [congelar] la memoria de un siglo en un instante" (p. 362). Transformada en una sola memoria viva y palpitante, sin fin y sin principio" (p. 418), Carlota recuerda todos los acontecimientos de su vida y todos los hechos que contribuyeron a la fundación y al malogrado final del imperio de Maximiliano en México. Así se convierte en una especie de conciencia histórica omnimoda que hace de alternativa poética a un "Juicio de la Historia" racional y objetivo. Y lo que es más, reemplaza a una "Historia Universal" que el autor considera imposible "y en última instancia indeseable" (p. 638). 


\section{LA TEORIA DE LA CREACION Y LA RE-CREACION POETICAS}

Las semejanzas que estamos indicando entre las tres novelas de Fernando del Paso se dan no solamente en la práctica textual sino también en un fondo teórico que sustenta a las obras. El autor orienta a sus lectores, incluyendo en cada novela una formulación de los principios teóricos sobre los que se asientan los tres textos.

En José Trigo es el narrador quien esboza un modelo poético para la obra, en la descripción que ofrece del arte verbal de la madrecita Buenaventura. De esta vieja centenaria quien comparte la narración con él, dice:

Manzanas incircuncisas, rosario, jaula, zancos: con éstas y otras palabras que sacó de su baúl mundo, comenzó la madrecita Buenaventura la historia siempre trunca o aún no comentada, y siempre detenida en los momentos en que la realidad y el sueño se confundían (p. 19).

El primer punto de interés que se desprende de la descripción es la noción de que la historia y el texto son microcosmos verbales. Según el narrador, la madrecita Buenaventura compone historias con palabras que sàca de un baúl, una especic de archivo o diccionario que es el origen. de la actividad creadora. Las palabras cstán cargadas de sentido poético, de acuerdo con los principios de una estética simbolista identificada con Edgar Allan Poe, a quien del Paso menciona durante una entrevista que coincidió con la publicación de José Trigo, haciendo suya una frase de Poe que elogiaba "el poder de las palabras". En segundo lugar, se intuye una negación de la función realista de la narración, y una preferencia por una concepción onírica e imaginativa del arte que concuerda con la "posición mística" admitida por el autor ${ }^{23}$ : esta postura plasma notablemente en la evocación de un vuelo fantástico por los trece cielos del mundo y los nueve infiernos del inframundo de la cosmología azteca, que el narrador emprende en la sección intermedia de José Trigo con la madrecita Buenaventura.

Un tercer fundamento poético de Jose Trigo es la concepción de la novela como espacio donde resucitan algunos cadáveres de la lengua. En la entrevista a la que acabamos de referirnos, el autor cita la definicion dada por Julio Cortázar del Diccionario de la Real Academia de la Lengua como "cementerio de las palabras", y se jacta de haber logrado en José Trigo la resurrección de muchas voces provenientes "del lenguaje castellano del siglo de Oro y del lenguaje híbrido que se habla en México actualmente"24. Para algunos lectores, "la epopeya del lenguaje" de del Paso en José Trigo no pasa de ser un alarde de virtuosismo

${ }^{23}$ Revelaciones y anticipaciones de Fernando del Paso y Miguel Angel Asturias, 3.

24 "Revelaciones y anticipaciones de Fernando del Paso y Miguel Angel Asturias", 3. 
lingúístico: brillante, audaz, y, en última instancia, gratuito ${ }^{25}$. Sin cmbargo, csa opinión ignora la relacion que hay entre la concepción delpasiana de la palabra como cucrpo redivivo, y la preocupación con la regencración y la resurrección que constituye el núcleo temático de José Trigo. Bien mirados, los aspectos lingüísticos se adecúan perfectamente al contenido de la novela que formula y da cucrpo a una poćtica de recupcración.

En Palinuro cl autor vuclve sobre cl tcma del Ienguaje y sus posibilidades artísticas, que dependerían de nuevo de una revitalización de las palabras "gastadas por los tiempos y las epidemias" (p.361) y un redescubrimicnto de los "misterios" de un lenguaje inocente y primordial. Considera también la cuestión de la sintaxis, y apunta a la posible renovación del lenguaje por medio de un cambio radical en las normas que rigen las mancras. de combinar las palabras.

Las ideas de del Paso con respecto al lenguaje se resumen esencialmente en una declaración de Walter, que reza así:

Nadie aprende nunca lo que es mamá o el color verde hasta que no se aprende la palabra mamá y la palabra verde. La literatura comienza, —al menos la literatura que a mí me interesa - cuando decimos mamá verde (p 520)

El punto de partida de estas reflexiones es el vínculo que existe entre una palabra y su referente. Para una escucla de lingüistas, los nominalistas, cl vínculo es natural c indiscutible, mientras que para los realistas, es de un carácter puramente arbitrario que se manticne gracias a la memoria y la costumbre. Walter indaga en las posibles consecuencias de una ruptura de los moldes lingüísticos habituales, y vislumbra la creación de una nueva identidad entre el lenguaje y el mundo de los objetos, que potenciaría una nucva litcratura subversiva.

Llevando su tcoría al terreno de la práctica, del Paso realiza numerosos experimentos con cl lenguaje figurado y la sintaxis cn Palinuro. Por un .lado, crea aluviones de metáforas (p. 330) del tipo de "mamá verde", como en los cjemplos de "pensamientos anaranjados", "corazas abstractas", y "olvidos aclimalados" (pp. 56 y 222). Por otro lado, jucga con las normas sintagmáticas y paradigmáticas de la lengua, aprovechando la "gimnasia csmcrilada [de las palabras]" ( 276 ) para violentar su orden esperado y convencional en la escructura de la frase. Los efectos que surten estos expcrimentos son los clásicos de la desfamiliarización propugnada por los formalistas y los estructuralistas; la filosofia que los inspira viene de los

${ }^{25}$ Uno de los críticos que adopta esta postura es Walter Langford en The Mexican Nove? Comes of Age (Notre Dame \& London: University of Notre Dame Press, 1971), p. 200. Quien entiende bien el aspecto verbal de José Trigo es David Bary, "Poesía y narración en cuatro novelas mexicanas", Cuadernos Americanos, CCXXXIV, 1 (cnero-febrero, 1981) 198-210. 
surrealistas, con quienes del Paso comparte el desco de cambiar nuestros hábitos lingüisticos, cognoscitivos, y experienciales.

El planteamicnto poético de la última novela de Fernando del Paso pone el énfasis en la invención y cl uso de la imaginación. Carlota, la máxima artífice del texto, proclama su inquebrantable voluntad de inventar la realidad del mundo, $o$, para ser más precisos, de inventarlo de nuevo. En un discurso de gratitud a Maximiliano, recuerda como "Tú [...] inventaste a México para mí. Tú que inventaste sus selvas y sus mares. Tú que con tus palabras inventaste el aroma de sus valles y cl fucgo de sus volcanes "(p. 71), y le insta a colaborar con ella en la cmpresa de "inventar de nuevo la historia" y de "inventar de nuevo nuestra vida" (p. 76).

Los principales instrumentos para facilitar esa tarea son los recuerdos y las palabras. Los recuerdos pueden recrear experiencias felices y transformar el pasado al gusto de Carlota, permiticndo una cvasión casi permanente de la realidad. Rodcada de fantasmas "que [le] hablan todo cl ticmpo" (p.116), Carlota se hunde cada vez más en el denso sucño de su locura, en un proceso que se relleja en el ambiente cada vez más fantasmal y onírico de la narración. Por lo que se refiere a las palabras, éstas son instrumentos con grandes poderes de evocación y "embrujamiento", tal como se demostró cn José Trigo y en Palinuro (p. 149). Pero su función principal es actuar como cstímulos y agentes de una resurrección simbólica. Contrastando a Maximiliano con los amantes imaginarios que ha olvidado, Carlota le hace saber que cs capaz de resucitarlo con sólo decir su nombre: "A ti [...] te puedo imaginar y a cllos no. Porque a ellos no los puedo resucitar y a ti sí. Tú vuclves a vivir cada vez que te nombro, cada vez que digo tu nombre: "Maximiliano" (p. 312).

Como último aspecto de interés Noticias cuenta con una teoría de la escrilura, de un gran interćs intrínscco, que da una clave sobre una posible interpretación de la novela. Centrada en cl personaje de Carlota, quien aparece en las primeras páginas scntada ante "un libro con las páginas en blanco y un frasco de tinta roja" (p. 22), la tcoría concibe cl acto de cscribir "como un río que nunca llega al horizonte, como un torrente que se precipita en cl infinito" (p. 492). Para Carlota, "Escribir así, de un hilo, juntando todas las palabras [...], en una sola línea sin pausas y sin espacio" (p.490) es un impulso biológico que cquivale, simplemente, a vivir. De allí la imagen de la sangre como tinta, que circula por el cuerpo de la historia y adorna cl cuerpo de Carlota tatuado "cn mi picl, donde todo quedó cscrito" (p. 608).

Entre otras cosas, la corricnte interminable de la narración de Carlota expresa su vitalidad inextinguible, y la identifica con un principio femenino que, en su caso, cstá hasta cicrto punto degradado. Consciente de su avanzada edad, la Empcratriz 
habla de "ese líquido corrupto que me corre por las venas" (p.607) y se anticipa a su muerte, que será tan inevitable como la de Anna Livia Plurabelle en Finnegans Wake: "Pronto, pronto, que se me va la vida y se me acaban las palabras", dice, cerca del final del libro (p. 665), haciendo eco de las últimas líneas de la novela de Joyce. No obstante, ella mantiene el ímpetu de su narración durante algunas páginas más, hasta que termina Noticias con una afirmaciun de la vida semejante a la que concluye Palinuro. Así, del Paso hace que prevalezca la vitalidad de las palabras y la escritura sobre el silencio de la muerte, en una reiteración de los valores espirituales que fundamentan su cosmovisión y su obra.

De este examen de las tres novelas de Fernando del Paso, se deduce que forman un todo coherente, basado en una unidad de intereses temáticos y formales y en unos principios poéticos que aparecen por toda la obra del autor. También se aprecia cómo Jose Trigo, Palinuro y Noticias perfilan una trayectoria lineal que va cobrando ímpetu y variedad conforme progresa la carrera literaria de del Paso. Desde 1959, cuando cmpieza a trabajar sobre José Trigo, hasta 1987 cuando publica Noticias, Fernando del Paso es un escritor mexicano en constante desarrollo y renovación. 